\title{
Survival Expectations of the Obese: Is Excess Mortality Reflected in Perceptions?
}

\author{
Tracy A. Falba and Susan H. Busch
}

\begin{abstract}
FALBA, TRACY A. AND SUSAN H. BUSCH. Survival expectations of the obese: is excess mortality reflected in perceptions? Obes Res. 2005;13:754-761.

Objective: This study compared self-reported subjective life expectancy (i.e., probability of living to age 75) for normalweight, overweight, and obese weight groups to examine whether individuals are internalizing information about the health risks due to excessive weight.

Research Methods and Procedures: Using data from the Health and Retirement Study, a total of 9035 individuals 51 to 61 years old were analyzed by BMI category. The primary outcome measure was individuals' reports about their own expectations of survival to age 75. Absolute and relative risks of survival were compared with published estimates of survival to age 75 .

Results: Consistently, higher levels of BMI were associated with lower self-estimated survival probabilities. Differences relative to normal weight ranged from $4.9 \%(p<0.01)$ for male nonsmokers to $8.8 \%(p<0.001)$ for female nonsmokers. However, these differences were substantially less than those obtained from published survival curve estimates, suggesting that obese individuals tended to underestimate mortality risks.

Discussion: Individuals appeared to underestimate the mortality risks of excessive weight; thus, knowledge campaigns about the risks of obesity should remain a top priority.
\end{abstract}

Key words: BMI, subjective survival, longevity, Health and Retirement Study

Received for review June 14, 2004

Accepted in final form February 10, 2005.

The costs of publication of this article were defrayed, in part, by the payment of page charges. This article must, therefore, be hereby marked "advertisement" in accordance with 18 U.S.C. Section 1734 solely to indicate this fact.

Department of Epidemiology and Public Health, Yale University School of Medicine, New Haven, Connecticut.

Address correspondence to Tracy A. Falba, Department of Epidemiology and Public Health, Yale University School of Medicine, P.O. Box 208034, 60 College Street, New Haven, CT 06520-8034.

E-mail: tracy.falba@yale.edu

Copyright (C) 2005 NAASO

\section{Introduction}

Recent research indicates that higher BMI levels are associated with a significant and substantial reduction in life expectancy $(1,2)$. One study estimates that obesity reduces life expectancy by 5.8 years among nonsmoking males and 7.1 years among nonsmoking females (2). A longer line of research has measured the increased mortality risk associated with BMI (3-14). However, if individuals do not accurately perceive these health risks associated with excess weight, they may not be making decisions about their health and associated behavior with full information.

Despite extensive literature demonstrating the effect of obesity on mortality, individuals may, for several reasons, have inaccurate perceptions about the substantial increased mortality risk associated with their own unhealthy weight. First, the health risks associated with obesity have only recently garnered attention from the U.S. Surgeon General (15) and the American media. Second, individuals may find it difficult to translate information about health risks to an assessment of whether their own weight puts them at risk. This is particularly true if the high prevalence of obesity in the population leads individuals to assess overweight as normal weight. Third, in the absence of a specific diagnosis of a health condition associated with obesity, individuals may not perceive a risk associated with their own excess weight. Fourth, providers may not be conveying the risks associated with unhealthy weight to their patients; one recent study suggests that in 1996, only $42 \%$ of obese patients received advice from a health care provider about their weight (16).

In this study, we considered a national sample of older Americans and compared the self-reported longevity expectations of normal-weight, overweight, and obese individuals (as determined by self-reported height and weight). We then considered whether (and how far) these estimates of life expectancy deviated from those in the medical literature (2). If individuals are underestimating the risks associated with obesity, this suggests that increased dissemination of information (e.g., government-sponsored public service announcements, physician advice) may help to motivate individual participation in either formal or informal weight loss activities and, ultimately, improve health and quality of life. 
Evidence suggests that, on average, individuals can reasonably predict their own mortality. In two distinct nonrandom samples, one researcher found that mean subjective life expectancies are somewhat consistent with current life tables, although subjective mortality curves tend to be somewhat flatter and exhibit greater variance than actual mortality data (17). Schoenbaum (18) considered the effect of smoking and smoking intensity on longevity expectations. Using the same data as this study, he found that longevity expectations generally fell as cigarette consumption increased and that heavy smokers tended to underestimate their risk of premature mortality. In another study using these same longitudinal data, economists examined whether individuals updated their subjective probability of death due to changes in health behaviors or new health events. These researchers found that smokers who quit did appropriately decrease their probability of death. Moreover, they found that longevity expectations did respond negatively to serious new health shocks (19).

To our knowledge, no one has analyzed whether individuals perceive the excess mortality risk of their own unhealthy weight. Using a large national sample of older Americans, we examined the association between weight and perceived health risk, as measured by an individual's subjective probability that they will live to age 75 . This outcome measure allowed us to consider three important research questions. First, we estimated whether individuals perceived any excess mortality associated with obesity and whether this excess risk generally increased for those of increased weight. Second, we considered whether the decrease in longevity expectation associated with obesity still exists once we controlled for whether the individual was previously diagnosed with two highly prevalent health conditions known to be associated with excess weight [i.e., diabetes $(5,20)$ and hypertension (21)]. Finally, although not precise, we compared the average change in self-reported expected longevity associated with obesity to the effect reported in the medical literature to see whether they are roughly the same order of magnitude (2).

\section{Research Methods and Procedures}

\section{Data}

The data for this study came from the Health and Retirement Study (HRS), ${ }^{1}$ a nationally representative sample of individuals born between 1931 and 1941 and their spouses (regardless of age eligibility). In 1992, the baseline wave questioned 12,652 individuals from 7702 households. Mexican Americans, blacks, and residents of Florida were oversampled. Baseline interviews were conducted in respondents' homes. The survey contains extensive information on

\footnotetext{
${ }^{1}$ Nonstandard abbreviations: HRS, Health and Retirement Study; CI, confidence interval.
}

individual's self-reported health behaviors, functional status, objective disease diagnoses, economic situation, and demographics. More detailed information on the HRS has been published elsewhere (22).

\section{Sample}

Of the 12,652 individuals for whom information was collected, 9825 were age-eligible (51 to 61 years old). Proxy interviews were omitted ( $n=465)$, as well as individuals who did not report their subjective probability of surviving to age 75 ( $n=206)$. Because we could not determine whether their weight was caused by poor health, $119(1.3 \%)$ individuals in the underweight category (defined below) were omitted, leaving a final sample of 9035.

We stratified the sample by both gender and current smoking status. The final analytic sample contained 2920 nonsmoking men, 3691 nonsmoking women, 1201 smoking men, and 1223 smoking women.

\section{Measures}

Outcome Variable: Individual's Subjective Survival to Age 75. Our primary outcome variable was an individual's report about their expectations of surviving to age 75 . Individuals were asked, "What do you think are the chances that you will live to be 75 or more?" This measure has been validated in prior research. It generally operates like a probability, the average is close to average probabilities in the population (e.g., from national life tables), and it is correlated with other variables that have similar correlations with actual outcomes (23).

BMI. BMI is a commonly used measure of weight adjusted for height (24). We calculated BMI from individual self-reports of height and weight. Following the NIH Clinical Guidelines on the Identification, Evaluation, and Treatment of Overweight and Obesity in Adults, we constructed five weight groups: underweight (BMI < 18.5), normal weight $(18.5 \leq \mathrm{BMI}<25)$, overweight $(25 \leq \mathrm{BMI}<30)$, obese $(30 \leq \mathrm{BMI}<35)$, and severely obese $(\mathrm{BMI} \geq 35)$. As reported above, we omitted the underweight individuals from the analyses because for this age group, being underweight may be the result of a health problem rather than the cause of any health problems $(25,26)$.

Smoking Status. We defined smoking status based on individuals' response to the question "Do you now currently smoke cigarettes?" Among nonsmokers, a history of smoking was used as a control variable in the analyses.

Diabetes and Hypertension. Although the primary analysis included all participants regardless of history of diabetes or hypertension, we also considered whether disease status was driving our results. Diagnosis of hypertension was identified by the response to the question "Has a doctor 
Table 1. Sample characteristics

\begin{tabular}{|c|c|c|c|c|c|}
\hline & All & $\begin{array}{c}\text { Male } \\
\text { nonsmokers }\end{array}$ & $\begin{array}{c}\text { Male } \\
\text { smokers }\end{array}$ & $\begin{array}{c}\text { Female } \\
\text { nonsmokers }\end{array}$ & $\begin{array}{c}\text { Female } \\
\text { smokers }\end{array}$ \\
\hline$N$ & 9035 & 2920 & 1201 & 3691 & 1223 \\
\hline \multicolumn{6}{|l|}{ Subjective survival probabilities } \\
\hline $\begin{array}{l}\text { Self-reported probability of survival } \\
\text { to age } 75(\mathrm{SD})\end{array}$ & $0.643(0.297)$ & $0.647(0.290)$ & $0.565(0.330)$ & $0.672(0.284)$ & $0.620(0.305)$ \\
\hline $\begin{array}{l}\text { Self-reported probability of survival } \\
\text { to age } 85(\mathrm{SD})\end{array}$ & $0.430(0.322)$ & $0.415(0.313)$ & $0.346(0.332)$ & $0.477(0.319)$ & $0.410(0.323)$ \\
\hline \multicolumn{6}{|l|}{ BMI } \\
\hline Normal weight $(18.5 \leq \mathrm{BMI}<25)(\%)$ & 34.0 & 25.4 & 38.4 & 35.4 & 45.8 \\
\hline Overweight $(25 \leq \mathrm{BMI}<30)(\%)$ & 41.5 & 51.2 & 44.4 & 35.2 & 34.8 \\
\hline Obese $(30 \leq \mathrm{BMI}<35)(\%)$ & 17.2 & 18.1 & 13.2 & 19.0 & 13.4 \\
\hline Severely obese $(35 \geq \mathrm{BMI})(\%)$ & 7.3 & 5.3 & 4.1 & 10.4 & 6.1 \\
\hline \multicolumn{6}{|l|}{ Smoking status } \\
\hline Former smoker $(\%)$ & 36.6 & 64.2 & & 38.7 & \\
\hline Current smoker (\%) & 26.8 & & 100 & & 100 \\
\hline \multicolumn{6}{|l|}{ Race } \\
\hline Black (\%) & 17.0 & 12.9 & 20.0 & 19.1 & 17.6 \\
\hline \multicolumn{6}{|l|}{ Ethnicity } \\
\hline Hispanic origin (\%) & 9.0 & 8.8 & 8.5 & 10.0 & 7.4 \\
\hline \multicolumn{6}{|l|}{ Demographics } \\
\hline Women $(\%)$ & 54.4 & & & & \\
\hline Less than high school education (\%) & 25.8 & 20.8 & 32.7 & 24.8 & 34.3 \\
\hline Age $>55(\%)$ & 49.5 & 52.2 & 49.7 & 50.3 & 45.1 \\
\hline Household income $<\$ 20,000(\%)$ & 27.8 & 17.4 & 29.7 & 30.7 & 41.9 \\
\hline Married (\%) & 75.3 & 85.9 & 75.2 & 72.2 & 59.6 \\
\hline \multicolumn{6}{|l|}{ Health Measures } \\
\hline Hypertension (\%) & 35.8 & 37.2 & 31.9 & 37.0 & 33.0 \\
\hline Diabetes $(\%)$ & 9.8 & 9.8 & 10.2 & 10.5 & 7.3 \\
\hline
\end{tabular}

Self-reported survival was reported on a scale from 0 to 10 and normalized to reflect a percentage likelihood. BMI was calculated from self-reported weight and height as BMI = weight (kilograms)/height (meters) squared. Current and former smoking status were based on self-reports of either current smoking or a history of having smoked more than 100 cigarettes. Hypertension and diabetes were based on self-reports of physician diagnoses of the conditions.

ever told you that you have high blood pressure or hypertension?" Diagnosis of diabetes was identified by the question "Has a doctor ever told you that you have diabetes or high blood sugar?"

Additional Covariates. Demographic control variables were also used in the analysis. These included education, age, race, ethnic origin, marital status, and household income. These variables are further described in Table 1.

\section{Analysis}

We first estimated least squares regressions to test whether subjective expectation of survival likelihood was significantly different with successively higher BMI categories. In these analyses, the normal-weight group was omitted as the reference group. Because these results were not compared with the extant medical literature, we captured additional variation within the obese group by separating these individuals into two groups: obese and severely obese.

Initially, we estimated an unadjusted model where the four dichotomous weight variables were the only covariates. To test whether demographic variables were driving our results, we then estimated an adjusted model controlling for the demographic covariates listed above. In all cases, we used Student's $t$ tests to determine whether the various 
weight categories were statistically significantly different from the normal-weight group.

A final analysis obtained results while also adjusting for whether the individual reported that they had been diagnosed with diabetes or hypertension. Because much of the effect of obesity on mortality is affected by underlying disease (27), adjusting for these factors provides an idea of the extent to which individuals account for the effect of obesity on survival only when it manifests in disease.

Next, we calculated the average subjective own probability of living to age 75 and corresponding SD for each of the three primary weight categories, by gender and smoking status. These values were then converted to risk ratios relative to the normal-weight category for each group. Confidence intervals (CIs) for the subjective risk ratios were calculated using the $\delta$-method to obtain the variance of the sample risk ratios (18).

Because we were interested in comparing these values with the true mortality risk from excessive weight, we sought the closest available estimates of life table data stratified by weight for survival to age 75 . We estimated actuarial probabilities of survival to age 75 from KaplanMeier curves reported by Peeters et al. (2) from the Framingham Heart Study data. These curves were reported by weight category stratified by gender and smoking status (2). The Framingham Heart Study baseline data were collected between 1948 and 1951, and more than 40 years of follow-up data on age of death were available. This study differs from the HRS because survival was available conditional on reaching age 40, whereas the HRS age range was from 51 to 61 years. To obtain probabilities of survival that would most accurately match the HRS sample, that is, survival conditional on living to the mean age of 55 , we divided the probability of surviving to age 75 conditional on reaching age 40 by the probability of surviving to age 55 for each of the four groups by weight category [Prob(surv 75/surv 55) $=$ Prob(surv 75/surv 40)/Prob(surv55/surv 40)].

\section{Results}

\section{Sample Characteristics}

In Table 1, we report the descriptive characteristics of the sample. The average self-reported probability of surviving to age 75 was $64.3 \%$ for the full sample, ranging from 56.5 for male smokers to $67.2 \%$ for female nonsmokers. The average self-reported probability of surviving to age 85 for the full sample was $43 \%$.

Thirty-four percent of the analytic sample were considered normal weight, $41.5 \%$ were overweight, and $24.5 \%$ were considered obese. Smokers tended to be less likely to be overweight or obese. Female nonsmokers had the highest rates of obesity, with over $29 \%$ reporting BMI of over 30 , of which one-third were severely obese. Nearly $36 \%$ of the sample had been diagnosed with hypertension and nearly $10 \%$ with diabetes.

\section{Expanded BMI Categories}

Table 2 tests the effect of successive BMI categories on the subjective expectation of living to age 75 for each of the four subsamples. For this analysis, we distinguished among obese $(30 \leq \mathrm{BMI}<35)$, severely obese $(35 \geq \mathrm{BMI})$, and overweight $(25 \leq \mathrm{BMI}<30)$. In the unadjusted model (column 1), all of the coefficients compared with normal weight were negative (as shown in Table 2 for the three weight categories). For the severely obese category, the coefficients compared with the normal-weight group ranged from -3.16 (not significant) for female smokers to -10.87 $(p<0.05)$ for male smokers.

\section{Adjusted Versus Unadjusted}

Column 3 of Table 2 presents these same coefficients and Student's $t$ tests for the adjusted model. The weighted intercepts for the normal group are different because in this case, they reflect the survival probability of a representative normal-weight individual. Overall, the coefficients changed very little, and the significance level was rarely affected.

\section{Comorbidities: Hypertension and Diabetes}

The final two columns of Table 2 show the regression coefficients when adjustments for the presence of diabetes or hypertension were added. As expected, both hypertension and diabetes each significantly reduced survival probabilities across subgroups. Although the majority of the coefficients are still negative, the effects of excessive weight were typically smaller. Severely obese male smokers continued to have an effect of $\sim 7 \%$ compared with the normal-weight group. For male nonsmokers, the effect was also concentrated among those who were severely obese. Female nonsmokers had a smaller but still significant effect of being overweight, obese, or severely obese. No effects were present for the female smoker group. Because there is an established pattern between diabetes and obesity $(5,20)$ and hypertension and obesity (21), these results are not surprising. A portion of the effect of obesity on survival operates through obesity-related diseases.

\section{Comparison of Unadjusted Means with Estimated Life Tables}

Table 3 compares the subjective own survival expectations of the HRS sample by BMI group with those estimates of actual risk in previously published studies. Similar to the estimated actuarial probabilities of surviving to age 75 (column 4), a monotonic pattern emerged for the subjective survival probability by weight group for each of the analytic subgroups (column 2). Higher levels of BMI were associated with lower own survival probabilities for all four subsamples (male nonsmokers, male smokers, female nonsmokers, and female smokers). 
Table 2. Multivariate model of subjective probability of survival to age 75

\begin{tabular}{|c|c|c|c|}
\hline & $\begin{array}{c}\text { Unadjusted } \\
\text { (Student's } t \text { test) }\end{array}$ & $\begin{array}{c}\text { Adjusted } \\
\text { (Student's } t \text { test) }\end{array}$ & $\begin{array}{c}\text { Adjusted for } \\
\text { hypertension } \\
\text { and diabetes } \\
\text { (Student's } t \text { test) }\end{array}$ \\
\hline Male nonsmokers & $n=2920$ & & \\
\hline Normal weight $t$ ( $(18.5 \leq \mathrm{BMI}<25)$ & $67.04(63.0)^{*}$ & $68.72(35.2)^{*}$ & $69.81(35.8)^{*}$ \\
\hline Overweight $(25 \leq \mathrm{BMI}<30)$ & $-2.34(-1.80) \S$ & $-2.30(-1.78) \S$ & $-1.47(-1.14)$ \\
\hline Obese $(30 \leq \mathrm{BMI}<35)$ & $-4.00(-2.43) \div$ & $-3.69(-2.24) \div$ & $-1.54(-0.93)$ \\
\hline Severely obese (35 $\geq$ BMI) & $-8.08(-3.16) \dagger$ & $-7.98(-3.14) \dagger$ & $-5.07(-1.98) \ddagger$ \\
\hline Male smokers & $n=1201$ & & \\
\hline Normal weight $(18.5 \leq \mathrm{BMI}<25)$ & $58.42(38.1)^{*}$ & $59.80(22.3)^{*}$ & $61.93(23.0)^{*}$ \\
\hline Overweight $(25 \leq \mathrm{BMI}<30)$ & $-2.11(-1.01)$ & $-2.32(-1.12)$ & $-1.05(-0.51)$ \\
\hline Obese $(30 \leq \mathrm{BMI}<35)$ & $-4.24(-1.40)$ & $-4.88(-1.63)$ & $-2.48(-0.82)$ \\
\hline Severely obese $(35 \geq \mathrm{BMI})$ & $-10.87(-2.19) \ddagger$ & $-11.65(-2.39) \dagger$ & $-6.74(-1.36)$ \\
\hline Female nonsmokers & $n=3691$ & & \\
\hline Normal weight $(18.5 \leq \mathrm{BMI}<25)$ & $71.48(91.7)^{*}$ & $76.08(55.0)^{*}$ & $76.62(55.47)^{*}$ \\
\hline Overweight $(25 \leq \mathrm{BMI}<30)$ & $-4.84(-4.38)^{*}$ & $-3.71(-3.39)^{*}$ & $-2.71(-2.47) \ddagger$ \\
\hline Obese $(30 \leq \mathrm{BMI}<35)$ & $-7.76(-5.87)^{*}$ & $-6.33(-4.81)^{*}$ & $-4.58(-3.44)^{*}$ \\
\hline Severely obese $(35 \geq \mathrm{BMI})$ & $-10.71(-6.55)^{*}$ & $-8.41(-5.11)^{*}$ & $-5.55(-3.29) \dagger$ \\
\hline Female smokers & $n=1223$ & & \\
\hline Normal weight $(18.5 \leq \mathrm{BMI}<25)$ & $64.11(49.7)^{*}$ & $68.10(28.8)^{*}$ & $69.08(29.09)^{*}$ \\
\hline Overweight $(25 \leq \mathrm{BMI}<30)$ & $-3.26(-1.66) \S$ & $-3.03(-1.53)$ & $-2.28(-1.15)$ \\
\hline Obese $(30 \leq \mathrm{BMI}<35)$ & $-6.06(-2.24) \div$ & $-6.18(-2.26) \ddagger$ & $-4.23(-1.53)$ \\
\hline Severely obese $(35 \geq \mathrm{BMI})$ & $-3.16(-0.84)$ & $-2.54(-0.66)$ & $0.98(0.25)$ \\
\hline
\end{tabular}

The first adjusted model includes controls for race, ethnicity, age, education, income, marital status, and smoking history. The second adds hypertension and diabetes history indicators.

$* p<0.001$.

$\dagger p<0.01$.

$\ddagger p<0.05$.

$\S p<0.10$.

IThe normal-weight group was the baseline for comparison with the other weight groups. For the adjusted regressions, this intercept represents a non-black, non-Hispanic individual in the $<56$-year-old age group with at least a high school education, household income more than $\$ 20,000$, who never smoked, and is not married.

Comparing the absolute subjective probabilities of survival with the absolute pseudolife table values (columns 2 and 3), subjective expectations tended to be somewhat pessimistic as a whole. However, this pessimism was least prevalent for the higher BMI groups. Assuming the values from the Framingham Heart Study were appropriate for this group, nonsmoking men who were normal weight were too pessimistic about survival, whereas nonsmoking obese men were only slightly pessimistic about survival (a difference of nearly $14 \%$ for the normal-weight group compared with only $1.5 \%$ for the obese group). A similar pattern was found for nonsmoking women. Both male and female smokers in the obese category were actually slightly optimistic about survival relative to the estimated life table value.

The risk ratios in columns 4 and 5 provide a relative comparison of the effect of BMI on subjective expectation of survival. This is useful if one presumes that pessimism was consistent across groups and that what really matters is the relative rankings of the groups. In all cases, the estimated actuarial risk ratio (column 5) for the obese BMI group falls outside the CI for the subjective risk ratio (column 4). For instance, the relative probability of survival of $79 \%$ for obese male nonsmokers compared with normal-weight male nonsmokers lies outside the range predicted from the subjective 
Table 3. Self-reported subjective and estimated life table probabilities of survival to age 75

\begin{tabular}{|c|c|c|c|c|c|c|}
\hline & \multirow[b]{2}{*}{$n$} & \multicolumn{2}{|c|}{ Mean survival probability } & \multicolumn{3}{|c|}{ Risk ratio (\%) } \\
\hline & & $\begin{array}{l}\text { Subjective* } \\
\text { (SD) } \dagger\end{array}$ & $\begin{array}{c}\text { Estimated } \\
\text { actual } \neq\end{array}$ & $\begin{array}{c}\text { Subjective } \\
(\%)\end{array}$ & $(95 \% \mathrm{CI})$ & $\begin{array}{l}\text { Estimated } \\
\text { actual }(\%)\end{array}$ \\
\hline \multicolumn{7}{|l|}{ Male nonsmokers } \\
\hline Normal weight $(18.5 \leq \mathrm{BMI}<25)$ & 741 & $0.670(0.276)$ & 0.808 & 100 & & 100 \\
\hline Overweight $(25 \leq \mathrm{BMI}<30)$ & 1495 & $0.641(0.290)$ & 0.718 & 96 & (91 to 100$)$ & 89 \\
\hline Obese $(\mathrm{BMI} \geq 30)$ & 684 & $0.621(0.304)$ & 0.636 & 93 & (84 to 102$)$ & 79 \\
\hline \multicolumn{7}{|l|}{ Male smokers } \\
\hline Normal weight $(18.5 \leq \mathrm{BMI}<25)$ & 461 & $0.584(0.328)$ & 0.637 & 100 & & 100 \\
\hline Overweight $(25 \leq \mathrm{BMI}<30)$ & 533 & $0.563(0.327)$ & 0.595 & 96 & (87 to 106$)$ & 93 \\
\hline Obese $(\mathrm{BMI} \geq 30)$ & 207 & $0.526(0.339)$ & 0.462 & 90 & (74 to 106$)$ & 73 \\
\hline \multicolumn{7}{|l|}{ Female nonsmokers } \\
\hline Normal weight $(18.5 \leq \mathrm{BMI}<25)$ & 1307 & $0.715(0.259)$ & 0.839 & 100 & & 100 \\
\hline Overweight $(25 \leq \mathrm{BMI}<30)$ & 1299 & $0.666(0.285)$ & 0.742 & 93 & (87 to 99$)$ & 88 \\
\hline Obese $(\mathrm{BMI} \geq 30)$ & 1085 & $0.627(0.303)$ & 0.645 & 88 & (79 to 96$)$ & 77 \\
\hline \multicolumn{7}{|l|}{ Female smokers } \\
\hline Normal weight $(18.5 \leq \mathrm{BMI}<25)$ & 560 & $0.641(0.299)$ & 0.733 & 100 & & 100 \\
\hline Overweight $(25 \leq \mathrm{BMI}<30)$ & 425 & $0.608(0.306)$ & 0.681 & 95 & (85 to 105$)$ & 93 \\
\hline Obese $(\mathrm{BMI} \geq 30)$ & 238 & $0.589(0.316)$ & 0.511 & 92 & (80 to 104$)$ & 70 \\
\hline \multicolumn{7}{|c|}{$\begin{array}{l}\text { Estimated life table probabilities were calculated from Kaplan-Meier curves reported in } 2 \text {, which used data from the Framingham Hear } \\
\text { Study. } \\
* \text { Represents mean expected probability of living from age at time of interview to at least age } 75 \text {. } \\
\dagger \text { Variance in survival expectations due to age and cohort differences across respondents. } \\
\ddagger \text { Represents actuarial probability of reaching age } 75 \text {, estimated as probability of survival conditional on surviving to mean age of HRS } \\
\text { sample. } \\
\S \text { Represents overweight/obese probability divided by normal weight probability. }\end{array}$} \\
\hline
\end{tabular}

risk ratio of $93 \%$ (84 to $102,95 \% \mathrm{CI}$ ). This would indicate that individuals of obese BMI are underpredicting the additional risks to survival posed by their weight.

\section{Discussion}

Comparing the longevity expectations of individuals with different BMIs, we found being overweight or obese had a negative and monotonic effect on self-reported longevity expectations, with obese individuals reporting between a $5 \%$ and $9 \%$ reduced likelihood of living to age 75 . It was striking that in all four groups, the average subjective expectation of survival declined with increased weight even after adjusting for other individual characteristics (i.e., race, ethnicity, age, education, income, and marital status). In fact, we found little change in the estimates of longevity expectations when adding these additional covariates. Thus, it appeared that individuals did perceive some increased mortality risk due to weight.

Next, we considered whether being diagnosed with a disease associated with obesity is the mechanism explaining differences in longevity expectations. When we controlled for the presence of hypertension or diabetes, the effects of excess weight on survival expectations were somewhat reduced and often not significant. However, it is notable that after separating out the effect of suffering from hypertension or diabetes on survival expectations, individuals did continue to perceive some of the health risks associated with their weight. Although not presented here, we found that even after omitting individuals diagnosed with hypertension and diabetes, individuals perceived some increased mortality risk associated with weight, although again the magnitude of the effect was greatly reduced and often no longer significant. One interesting consideration might be whether obese individuals who have remained in otherwise good health until this age remain at greater risk for survival. Unfortunately, such specific life tables are not currently available.

In our final analysis, we then compared these estimates with published estimated life tables (2). Although differences between the two samples limit the conclusions that 
can be drawn, we found that individuals significantly underestimated the mortality risk associated with obesity (with the true absolute risk difference being a reduction of between $17 \%$ and $22 \%$ ). This false optimism was most pronounced among smokers who were also obese. Interestingly, previous research showed that heavy smokers were optimistic about their survival; that this optimism among smokers was concentrated in the obese weight category may suggest that information about the risks of smoking needs to be focused on this group.

The results presented here should be interpreted with some caution. First, the comparison with published estimated life tables is not precise. To be most accurate, data on actual age at death would be compared with previously recorded longevity expectations. Another more valid comparison would be data from comprehensive populationbased life tables stratified by BMI. Neither of these datasets is currently available. We considered data from a published study that used comprehensive longitudinal data from a single age cohort. Due to differences in age range and cohort, these estimates were not perfectly consistent with our data. Moreover, compared with population life tables, these data were from a relatively small sample $(N=3607)$ (2). Thus, to the extent that the effect of increased BMI on life expectancy differs by age cohort, the estimates presented here may not be directly comparable. Although these problems may affect the magnitude of the effect, these biases would have to be severe for the qualitative results to change. However, other published reports have estimated the years of life lost to be smaller (1).

Second, the measure of weight we considered (BMI) has several limitations. Although self-reported BMI is commonly used in the medical literature and has been shown to be correlated with true height and weight, data from the National Health and Nutrition Examination Study suggest that some reporting bias may exist (28). Unfortunately, no direct measures of height and weight were available. It is likely that a systematic underreporting of weight among obese individuals would bias our coefficient on obesity downward. Specifically, some individuals who reported normal BMI may, in fact, have been overweight or obese. If they nevertheless accounted for their excess weight in projecting survival, this would, on average, have led to an understatement of the effect of excess weight. Theoretically, this is problematic for the comparison with life table estimates of the effect of weight on survival.

A final potential problem (common to all survey data) is that information regarding important confounding variables may be unavailable. However, we were reassured by the fact that adding basic covariates had little effect on our results. Most other variables correlated with both weight and mortality (e.g., cardiovascular disease, physical fitness) may play a role but might be best excluded when looking for the aggregate effect of obesity on survival expectations.
Although beyond the scope of this study, we did preliminarily examine the effect of disease not associated with obesity (e.g., lung disease). As expected, there was no effect on our primary results when this disease indicator was added to the model. Other variables related to obesity (such as cardiovascular disease) affected the models similarly to the adjustments for diabetes and hypertension. However, because part of the effect of obesity operates through these diseases, we prefer the partially adjusted results. This is also most useful for life table comparisons.

\section{Conclusion/Policy Implications}

Obesity and overweight have a high and growing prevalence in the population (29-32). According to one study, between 1991 and 2000, overweight and obesity among adults increased from $45 \%$ to $56.4 \%$ (31). This emerging epidemic will yield significant losses in terms of morbidity and mortality, as well as associated economic costs $(33,34)$. Many reasons for the increase in weight have been suggested in the literature; these include increases in sedentary occupations (35), increases in the prevalence of fast food outlets (36), declines in the availability of healthy food (36), and the growing suburbanization of our society (37). The research presented here suggests that education that increases an individual's knowledge of the health risks of obesity may be an important step on the path to individual adoption of healthy behaviors. Meanwhile, one recent study using the CDC's Behavioral Risk Factor Surveillance System suggested that less than one-half of obese patients received advice from their physician about losing weight (16). This is in contrast to smokers. Based on data from the CDC's Behavioral Risk Factor Surveillance System in 1997, $70 \%$ of smokers received advice about quitting, conditional on having a routine visit in the prior year (38). One would expect that underestimation of the health risks will reduce participation in activities that reduce weight or prevent weight gain. Thus, public policies to disseminate this information may be a critical component in any policy.

\section{Acknowledgment}

There was no outside funding/support for this study.

\section{References}

1. Fontaine KR, Redden DT, Wang C, Westfall AO, Allison DB. Years of life lost due to obesity. JAMA. 2003;289:18793.

2. Peeters A, Barendregt JJ, Willekens F, Mackenbach JP, Al Mamun A, Bonneux L. Obesity in adulthood and its consequences for life expectancy: a life-table analysis. Ann Intern Med. 2003;138:24-32.

3. Lee IM, Manson JE, Hennekens CH, Paffenbarger RS Jr. Body weight and mortality: a 27-year follow-up of middleaged men. JAMA. 1993;270:2823-8. 
4. Harris T, Cook EF, Garrison R, Higgins M, Kannel W, Goldman L. Body mass index and mortality among nonsmoking older persons: the Framingham Heart Study. JAMA. 1988; 259:1520-4.

5. Lew EA, Garfinkel L. Variations in mortality by weight among 750,000 men and women. J Chronic Dis. 1979;32: 563-76.

6. Calle EE, Thun MJ, Petrelli JM, Rodriguez C, Heath CW Jr. Body-mass index and mortality in a prospective cohort of U.S. adults. New Engl J Med. 1999;341:1097-105.

7. Folsom AR, Kaye SA, Sellers TA, et al. Body fat distribution and 5-year risk of death in older women. JAMA. 1993;269: 483-7.

8. Garfinkel L. Overweight and mortality. Cancer. 1986; 58(Suppl 8):1826-9.

9. Durazo-Arvizu R, Cooper RS, Luke A, Prewitt TE, Liao Y, McGee DL. Relative weight and mortality in U.S. blacks and whites: findings from representative national population samples. Ann Epidemiol. 1997;7:383-95.

10. Diehr P, Bild DE, Harris TB, Duxbury A, Siscovick D, Rossi M. Body mass index and mortality in nonsmoking older adults: the Cardiovascular Health Study. Am J Public Health. 1998;88:623-9.

11. Cornoni-Huntley JC, Harris TB, Everett DF, et al. An overview of body weight of older persons, including the impact on mortality: the National Health and Nutrition Examination Survey I: Epidemiologic Follow-up Study. J Clin Epidemiol. 1991;44:743-53.

12. Singh PN, Lindsted KD. Body mass and 26-year risk of mortality from specific diseases among women who never smoked. Epidemiology. 1998;9:246-54.

13. Stevens J, Cai J, Pamuk ER, Williamson DF, Thun MJ, Wood JL. The effect of age on the association between body-mass index and mortality. $N$ Engl J Med. 1998;338:1-7.

14. Allison DB, Fontaine KR, Manson JE, Stevens J, VanItallie TB. Annual deaths attributable to obesity in the United States. JAMA. 1999;282:1530-8.

15. U.S. Department of Health and Human Services. The Surgeon General's Call to Action to Prevent and Decrease Overweight and Obesity 2001. Washington, DC: U.S. Department of Health and Human Services, Public Health Service, Office of the Surgeon General; 2001.

16. Galuska DA, Will JC, Serdula MK, Ford ES. Are health care professionals advising obese patients to lose weight? JAMA. 1999;282:1576-8.

17. Hamermesh DS. Expectations, life expectancy, and economic behavior. $Q J$ Econ. 1985;10:389-408.

18. Schoenbaum M. Do smokers understand the mortality effects of smoking? Evidence from the Health and Retirement Survey. Am J Public Health. 1997;87:755-9.

19. Smith VK, Taylor DH Jr., Sloan FA. Longevity expectations and death: can people predict their own demise? Am Econ Rev. 2001;91:1126-34.

20. Colditz GA, Willett WC, Rotnitzky A, Manson JE. Weight gain as a risk factor for clinical diabetes mellitus in women. Ann Intern Med. 1995;122:481-6.
21. Brown CD, Higgins M, Donato KA, et al. Body mass index and the prevalence of hypertension and dyslipidemia. Obes Res. 2000;8:605-19.

22. Juster FT, Suzman R. An overview of the Health and Retirement Study. Journal of Human Resources Suppl. 1995;30: S7-56.

23. Hurd MD, McGarry K. Evaluation of the subjective probabilities of survival in the Health and Retirement Study. J Hum Res. 1995;30(suppl):S268-92.

24. Executive summary of the clinical guidelines on the identification, evaluation, and treatment of overweight and obesity in adults. Arch Intern Med. 1998;158:1855-67.

25. Manson JE, Stampfer MJ, Hennekens CH, Willett WC. Body weight and longevity: a reassessment. JAMA. 1987;257: 353-8.

26. Troiano RP, Frongillo EA Jr., Sobal J, Levitsky DA. The relationship between body weight and mortality: a quantitative analysis of combined information from existing studies. Int $J$ Obes Relat Metab Disord. 1996;20:63-75.

27. Manson JE, Willett WC, Stampfer MJ, et al. Body weight and mortality among women. N Engl J Med. 1995;333:67785 .

28. Rowland ML. Self-reported weight and height. Am J Clin Nutr. 1990;52:1125-33.

29. Mokdad AH, Ford ES, Bowman BA, et al. Prevalence of obesity, diabetes, and obesity-related health risk factors, 2001. JAMA. 2003;289:76-9.

30. Mokdad AH, Serdula MK, Dietz WH, Bowman BA, Marks JS, Koplan JP. The spread of the obesity epidemic in the United States, 1991-1998. JAMA. 1999;282:1519-22.

31. Mokdad AH, Bowman BA, Ford ES, Vinicor F, Marks JS, Koplan JP. The continuing epidemics of obesity and diabetes in the United States. JAMA. 2001;286:1195-200.

32. Flegal KM, Carroll MD, Kuczmarski RJ, Johnson CL. Overweight and obesity in the United States: prevalence and trends, 1960-1994. Int J Obes Relat Metab Disord. 1998;22: $39-47$.

33. Sturm R, Wells KB. Does obesity contribute as much to morbidity as poverty or smoking? Public Health. 2001;115: 229-35.

34. Wolf AM, Colditz GA. Current estimates of the economic cost of obesity in the United States. Obes Res. 1998;6:97-106.

35. Philipson T. The world-wide growth in obesity: an economic research agenda. Health Econ. 2001;10:1-7.

36. Brownell KD, Horgen KB. Food Fight: The Inside Story of the Food Industry, America's Obesity Crisis, and What We Can Do About It. Chicago, IL: McGraw-Hill; 2003.

37. Ewing R, Schmid T, Killingsworth R, Zlot A, Raudenbush S. Relationship between urban sprawl and physical activity, obesity, and morbidity. Am J Health Promot. 2003; 18:47-57.

38. Denny CH, Serdula MK, Holtzman D, Nelson DE. Physician advice about smoking and drinking: are U.S. adults being informed? Am J Prev Med. 2003;24:71-4. 